\title{
ESTIMATES OF THE NUCLEAR DESIGN REQUIREMENT FOR THE PECHORA-KAMA CANAL PROJECT
}

\author{
Milo D. Nordyke
}

January 16, 1979

Work performed under the auspices of the U.S. Department of

Energy by the UCLLL under contract number W.7405-ENG.48.

\section{is}
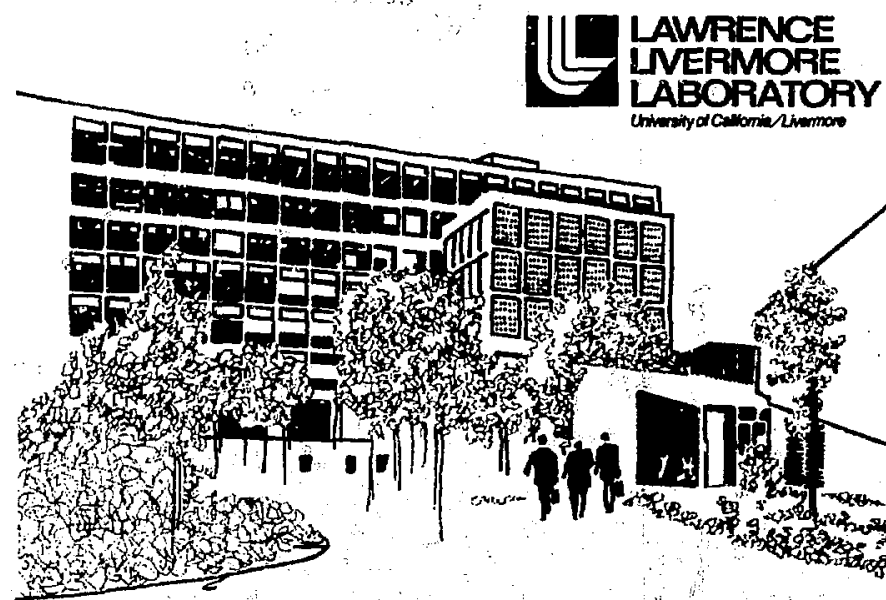

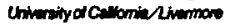
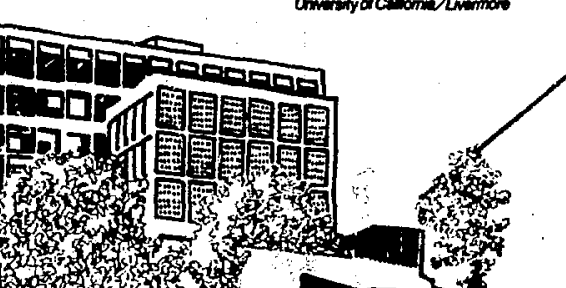

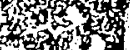

nosis
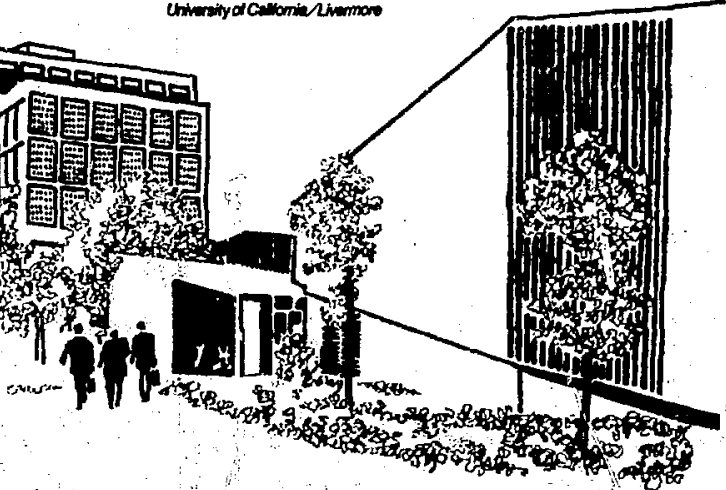

$$
\text { MASTER }
$$

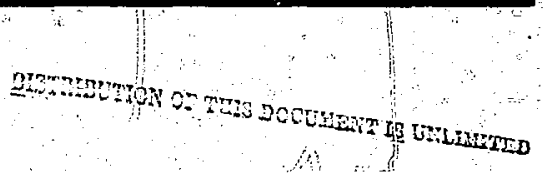




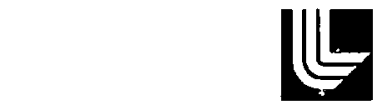

\title{
LAWRENCE LIVERMORE LABORATORY
}

University of Calfomia/Livemore,Califorria/94550

UCRL-52635

\section{ESTIMATES OF THE NUCLEAR DESIGN REQUIREMENT FOR THE PECHORA-KAMA CANAL PROJECT}

\author{
Milo D. Nordyke
}

MS. date: January 16, 1979

Tin report was " Thi reper the

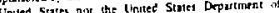

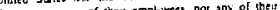

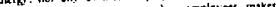

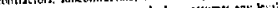

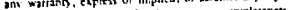

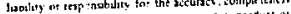

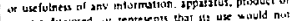

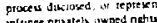




\section{CONTENTS}

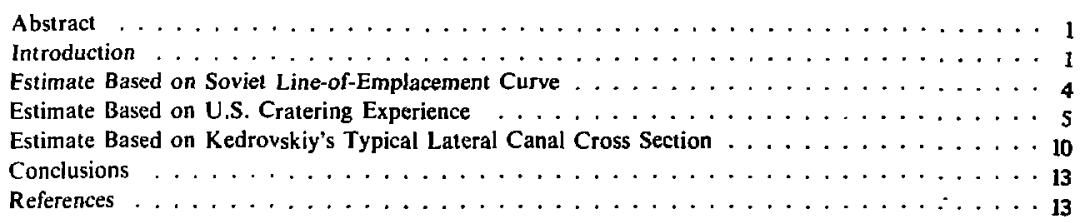




\section{ESTIMATES OF THE NUCLEAR DESIGN REQUIREMENT FOR THE PECHORA-KAMA CANAL PROJECT}

\section{ABSTRACT}

The Soviet Union is considering the use of nuclear explosives to excavate a portion of the Pechora-Kama Canal to divert water from northward-flowing rivers into the Caspian Sea. The Soviets have provided a general description of the Canal project, but detailed axalyses of the nuclear design, including yiclds and number of nuclear charges, have never been published. We present estimates for the nuclear design based on three different approaches. Because of the meager amount of data provided by Soviet scientists, we made a variety of assumptions, based on U.S. experience, regarding media properties and Jesign parameters. The resulting estimates are strongly dependent upon these assumptions. We found that reasonable sets of assumptions can be found which lead to results in agreement with the published Soviet estimates for the total yield and total number of explosives. Our results also indicate that the nuclear canal can be constructed, under most assumptions, to meet all identified Soviet criteria using only nuclear explosives with yields less than or equal to $150 \mathrm{kt}$.

\section{INTRODUCTION}

Over the last 10 years, Soviet scientists have spoken often and published many papers describing their plans for using nuclear explosives to excavate a portion of the Pechora-Kama (Kolva) Canal. (For more details on the proposed Canal project, see Ref. 1.) However, they have provided little factual data on which to base an independent analysis of the explosive requirements for this project. The most commonly quoted statement is that of Kedrovskiy in 1970. He stated that the portion of the Canal to be excavated with nuclear explosives would be 65 $\mathrm{km}$ long, have a cross section of $5000 \mathrm{~m}^{2}$, and require about 250 individual charges emplaced at depths ranging from 150-285 m. Further, these charges would be fired in groups of up to 20, with a total yield of 3 Mt per group. Privately, ${ }^{3}$ the Soviets indicated the yield of individual explosives would be between $40-500 \mathrm{kt}$, with a total yield of $36 \mathrm{Mt}$. Reports ${ }^{4}$ published later stated the required cross section would be reduced from 5000 to $3000 \mathrm{~m}^{2}$. Recent private remarks ${ }^{5}$ indicated the length considered for nuclear excavation has been reduced from 65 to $53 \mathrm{~km}$ and the required cross section may have been further reduced to $2000 \mathrm{~m}^{2}$.

The most useful data available to analyze this project is the topographic cross section along the alignment shown in Fig. I. Nuclear excavation is indicated for the left half (northern portion)* of the cross section shown in Fig. 1. The geological structure along the alignment is also crudely shown. The geology appears to consist of surficial, unconsolidated sediments $20-50 \mathrm{~m}$ thick (except for a $120 \mathrm{~m}$ deep trough about $36 \mathrm{~km}$ from the northern end) underlain by sandstone, siltstone, and argillite. Figure 1 also indicates both the planned water level for the Canal (about $130 \mathrm{~m}$ ) and the line-ofemplacement of the nuslear charges. This water level probably also corresponds roughly to the existing water table in the area. ${ }^{4}$ Figure 2 shows a typical lateral cross section for such a canal produced by a row of discrete charges. The useful portion of the cross section, indicated by crosshatching, is considerably smaller than the *As indicated by comparison with data in Ref. 4 . 


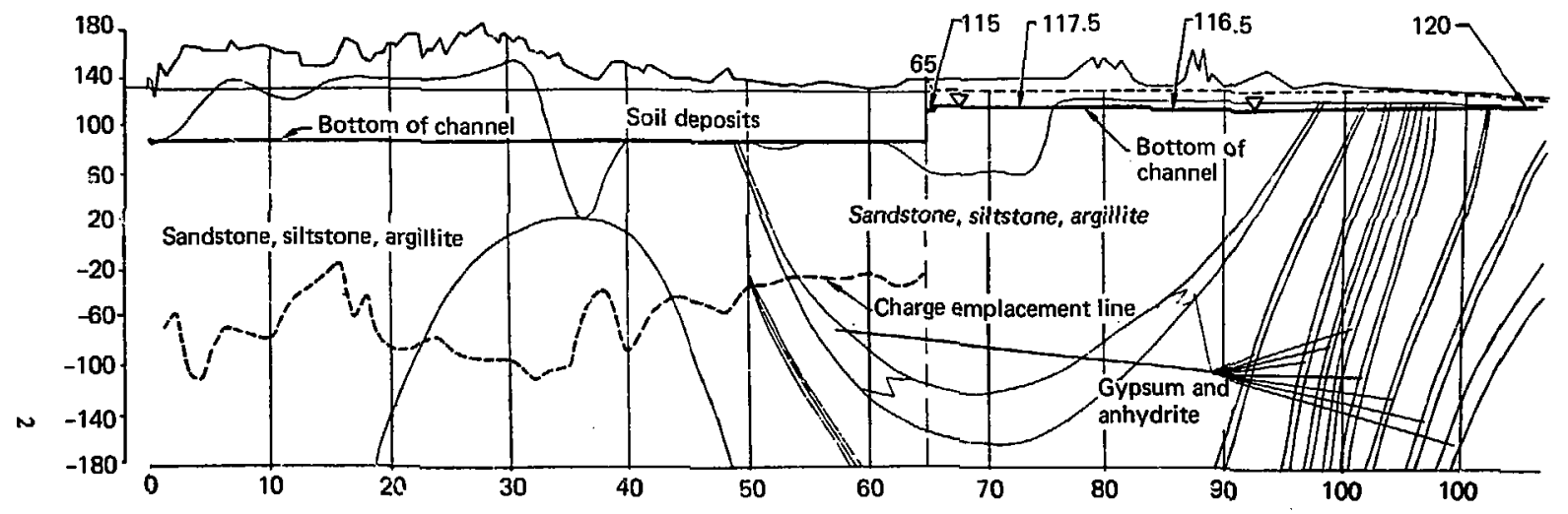

FIG. 1. Cross section along axis of Pechora-Kama Canal. 


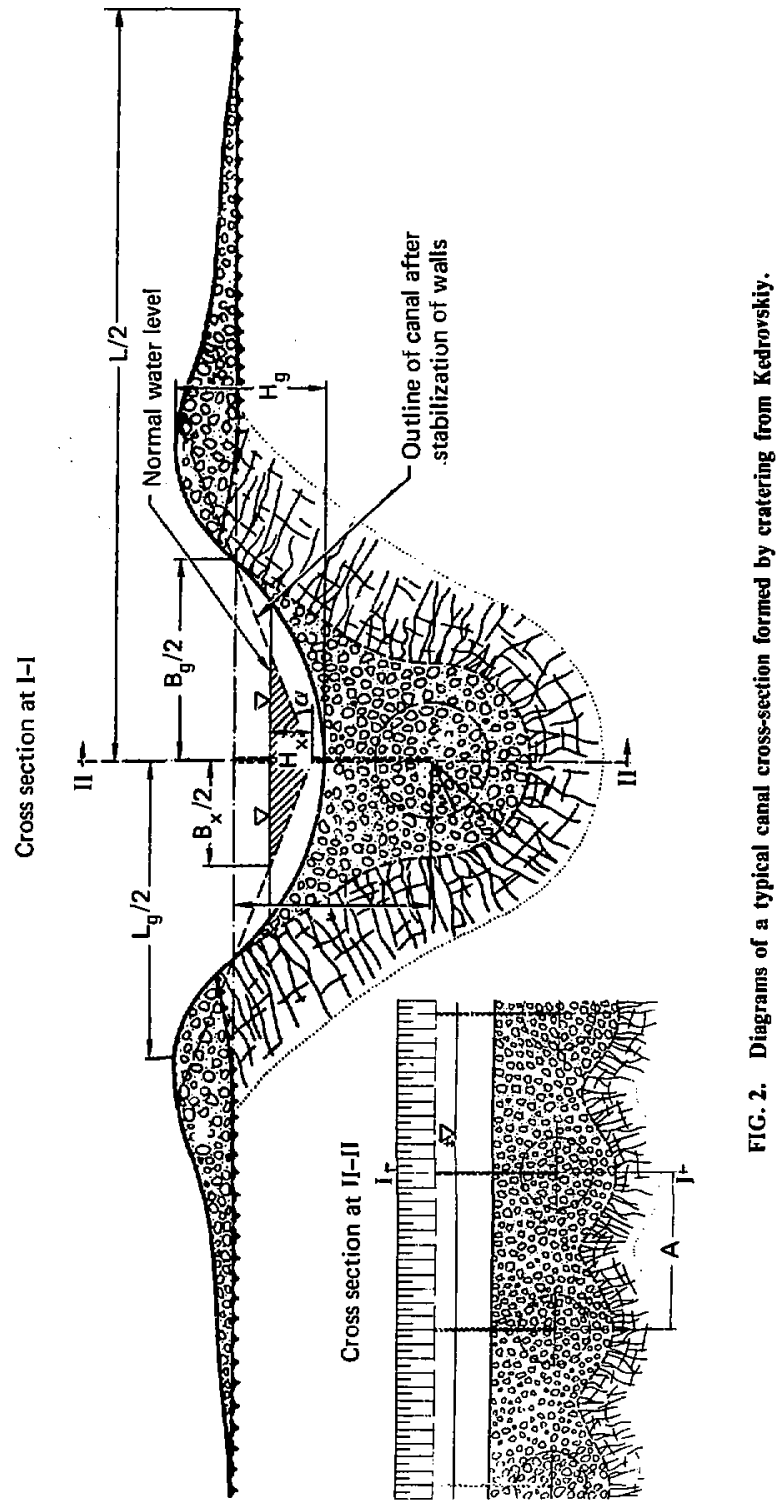


available cross section produccd by the explosion. Notations in Fig. 2 indicate the useful cross section is the residual area after allowance is made for stabilization of the crater slopes. (Both Figs. I and 2 are taken (rom Ref. 2.)

We can make estimates of the explosive requirements for construction of this Canal by a numher of different methois, although the paucity of available data makes it impossible to make definitive statements. One method is to base the calculations on the line-of-emplacement curve in Fig. I by assuming a constant scaled depth-ofburial. A second method calculates the explosive requirements: based solely on the topographic cross section ${ }^{2}$ of Fig. I and U.S. knowledge of the cratering properties of comparable materials. A third method uses tie design assumptions inherent in the canal cross section ${ }^{3}$ of Fig. 2 and the topographic cross section along the canal alignment. ${ }^{2}$ Estimates based on these three methods are described below.

\section{ESTIMATE BASED ON SOVIET LINE-OF-EMPLACEMENT CURVE}

We can estimate the number and yield of nuclear charges planned for this project from the charge emplacement line shown in Fig. 1 . Postulating a family of explosives, $W_{i}$, ranging from 50-600 kt. we can calculate the corresponding required depths-of-burial, $Z_{i}$, assuming a constant scaled depth-of-burial, $Z_{s}$, of $43 \mathrm{~m} / \mathrm{kt}^{1 / 3.4}$ (as used for 1004, the Soviet 125-k1 nuclear crater). (See Table 1.) We examined Fig. 1 to estimate the total number of kilometers, $\Delta \mathrm{L}$, of the route that had depths-of-burial between the ones shown in Table 1 . These lengths are then used to estimate the number of charges of each yield required.

If we assume a spacing for the charges equal to the depth-of-burst (i.e., $S / Z=1.0$ ), this calculation resuls in a total required number of charges of 287. somewhat in excess of the 250 cited by Kedrovskiy. ${ }^{2}$
If we use a spacing equal to 1.3 times the depth-ofburial, a value generally recommended in the Soviet literature, we get a total of 223 charges, somewhat less than 250. (See the last column of Table 1.) While this agreement on the total number of charges is fairly good, the total yields for these two cases are 93 and $70 \mathrm{Mt}$, respectively, significantly greater than Kedrovskiy's $36 \mathrm{Mt}$. If we use a scaled depth-of-burst of $50 \mathrm{~m} / \mathrm{kt}^{1 / 3.4}$, the maximum individual yield is reduced to $400 \mathrm{kt}$, but the total number of charges remains almost unchanged. The total yields, however, are reduced to 56 and $44 \mathrm{Mt}$, respectively, much closer to Kedrovskiy's $36 \mathrm{Mt}$. This method only checks the internal consistency of the numbers Kedrovskiy provided and does not really address the question of what yields are really needed to carry out the desired task.

TABLE 1. Estimated explosives requirements for the Pechora-Kama Canal. These estimates are based on explosive depthsof-burial in Fig. 1 for $Z_{s}=43 \mathrm{~m} / \mathrm{kt}^{1 / 3.4}$.

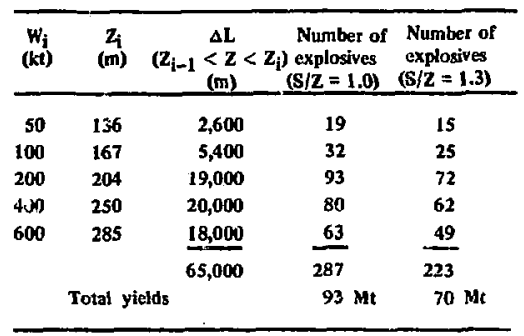




\section{ESTIMATE BASED ON U. S. CRATERING EXPERIENCE}

An alternative approach is to calculate the explosive requirements on the basis of the topographic cross section shown in -Fig. 1, assumptions regarding the desired canal cross section, and the cratering properties of the media. The latter are based on U. S. cratering experience. Although the results of this calculation are very sensitive to the assumptions, they do serve to indicate bounds for the problem.

A substantial amount of research by the Corps of Engineers ${ }^{6}$ indicated that row craters have hyperbolic cross sections. Therefore, we can describe the cross section of a row crater in terms of its halfwidth, $r$, as a function of the distance from the bottom, d, by

$$
(d+b)^{2}-r^{2} m^{2}=b^{2}
$$

or

$$
\mathrm{r}^{2}=\frac{\mathrm{d}^{2}+2 \mathrm{bd}}{\mathrm{m}^{2}}
$$

where $m$ is the asymptotic slope of crater walls. Figure 3 illustrates these relationships. The parameter $b$ is defined by the values of $r$ and $d$ at the level of the original ground surface, $R$ and $D$, respectively, from

$$
\mathrm{b}=\frac{\mathrm{m}^{2} \mathrm{R}^{2}-\mathrm{D}^{2}}{2 \mathrm{D}}
$$

Since $R=R_{s} W^{1 / 3.4}$ and $D=D_{s} W^{1 / 3.4}$, where $R_{s}$ and $D_{s}$ are the scaled crater half-width and depth, we can write

$$
b=b_{s} w^{1 / 3.4}
$$

where

$$
b_{s}=\frac{m^{2} R_{s}^{2}-D_{s}^{2}}{2 D_{s}} .
$$

If we wish to have a given area, $A$, with a depth, c, at the bottom of such a hyperbolic cross section, we can show that

$$
A=\frac{b^{2}}{m} f(x)
$$

where

$$
\mathbf{x}=\frac{\mathbf{c}}{\mathrm{b}}
$$

and

$f(x)=(x+1)\left(x^{2}+2 x\right)^{1 / 2}-\ln \left[(x+1)+\left(x^{2}+2 x\right)^{1 / 2}\right]$.

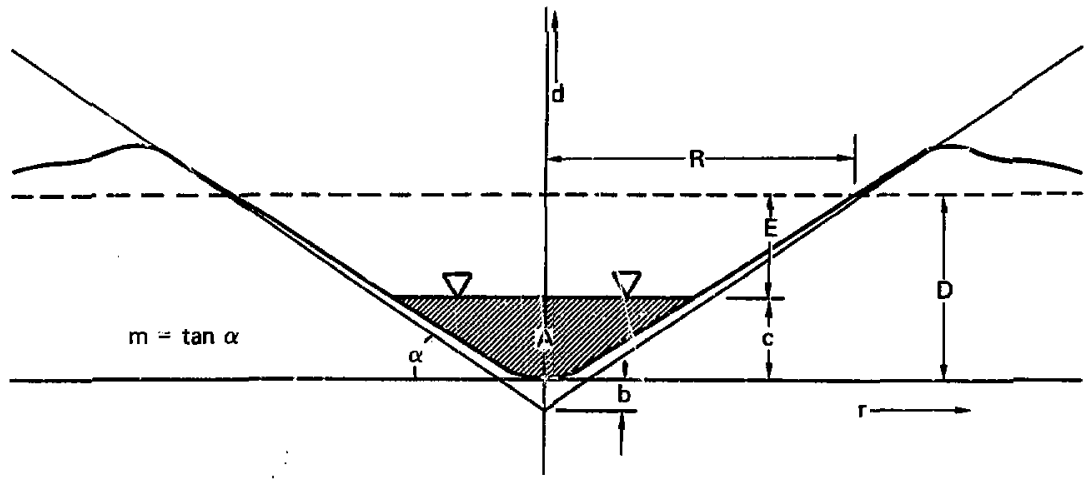

FIG. 3. Typical hyperbolic row crater cross section. 
Figure 4 is a plot of $f(x)$ for values of $x$ between 0 and 10.

The elevation, $\mathrm{E}$, through which a given yield, $W$, can construct a canal with a usable cross section, $A$, and a water depth, $c$, is thus given by

$E=D-c=D-x b=w^{1 / 3,4}\left(D_{s}-x b_{s}\right)$.

Note that here $E$ is the elevation above the water surface. (See Fig. 3.) Knowing A, we can culculate $f(x)$ from $E_{q}$. (2) and determine $x$ from Fig. 4. This then permits $E$ to be determined as a runction of $W$ from $\mathrm{Eq}$. (4).

We ussume, conservatively, that the media along the Pechora-Kama Canal route will crater in a manner similar to U.S. experience in dry, hard rock. This leads to a choice of scaled parameters of

$$
\begin{aligned}
& \mathrm{R}_{\mathrm{s}}=41 \mathrm{~m} / \mathrm{kt}^{1 / 3.4}, \\
& \mathrm{D}_{\mathrm{s}}=24 \mathrm{~m} / \mathrm{kt}^{1 / 3.4}, \\
& \mathrm{Z}_{\mathrm{s}}=40 \mathrm{~m} / \mathrm{kt}^{1 / 3.4},
\end{aligned}
$$

and

$$
\mathrm{m}=0.7 \text {. }
$$

These values give

$$
b_{s}=5.16
$$

which leads to the curves of $E$ vs $W$ for areas of 2000, 3000, 5000, and $10,000 \mathrm{~m}^{2}$ shown in Fig. 5 . The $10,000 \mathrm{~m}^{2}$ cross section is included to provide a case with a safety factor of 2 for possible slumping and scalloping of the crater walls.

To obtain a quantitative estimate of the length of the Canal occurring at various elevations, the topographic cross section shown in Fig. 1 for the northern $65 \mathrm{~km}$ of the Canal route was smoothed and replotted at a 20:1 exaggerated vertical scale in Fig. 6. The total length of the route occurring in various $4-\mathrm{m}$ intervals was then calculated and is presented in Table 2.

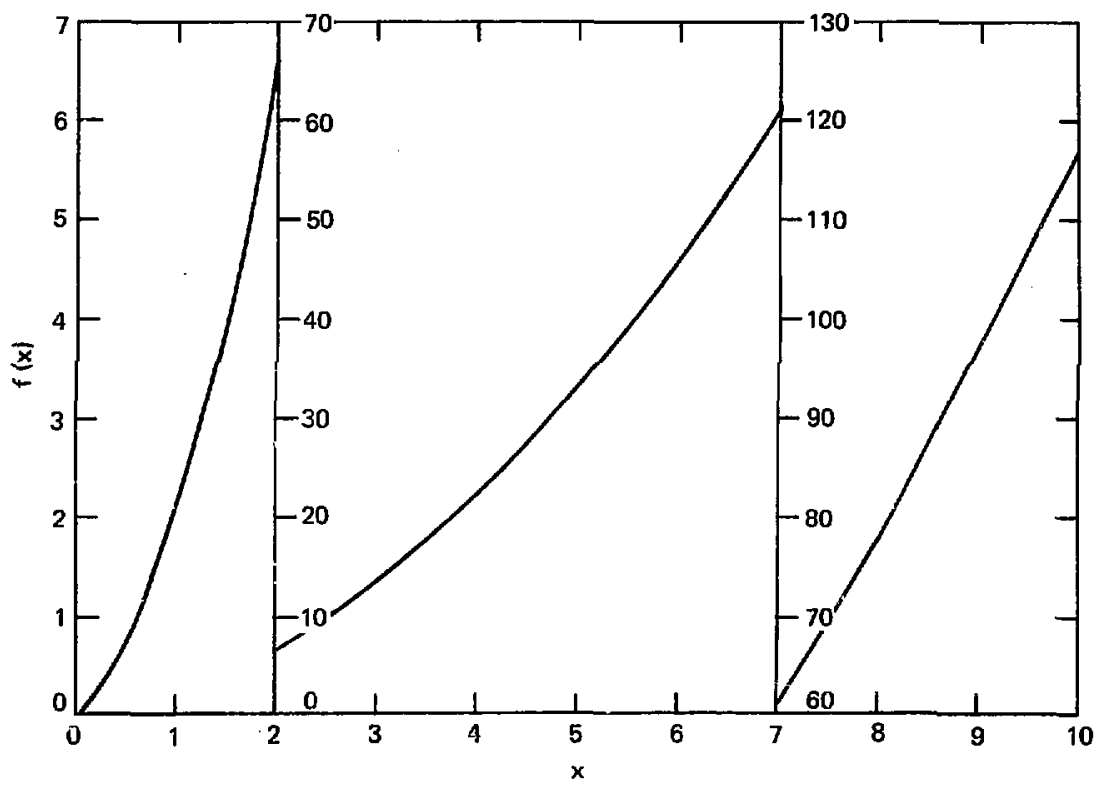

FIG. 4. Fiot of $f(x)$ vs $x$. 


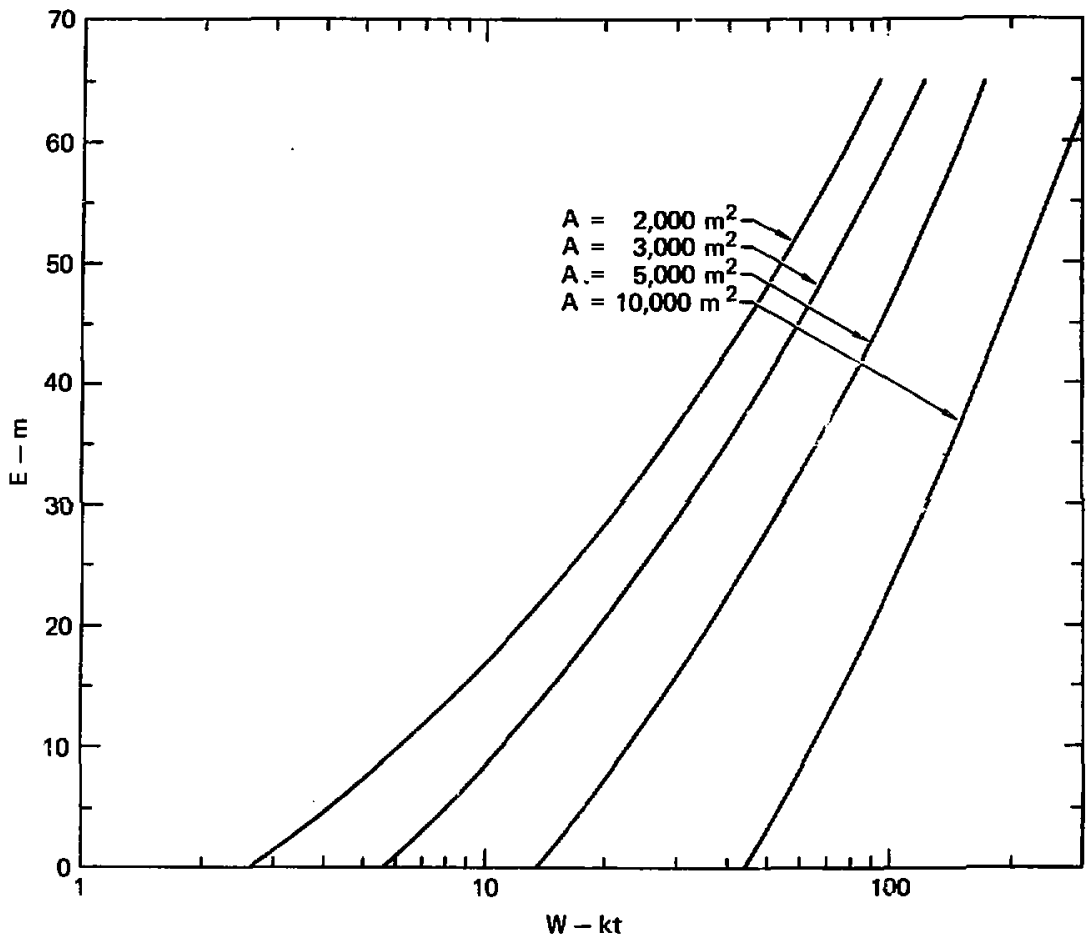

FIG. 5. Water surface elevation vs yield and cross-sectional area for dry, hard-rock cratering parameters.

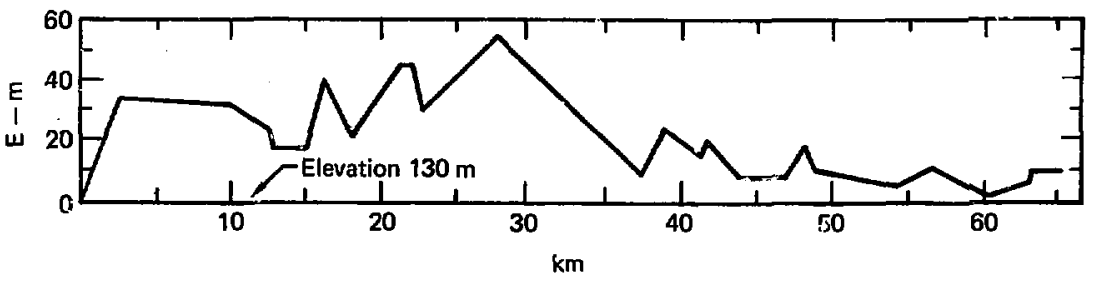

FIG. 6. Topographic surface from Fig. 1 with entanced vertical scale. 
TABLE 2. Aggregate length of constant elevation intervals far the Pechora-Kama Canal.

\begin{tabular}{cc}
\hline $\begin{array}{c}\text { Elevation interval } \\
\text { above } 130 \mathrm{~m} \\
\text { (m) }\end{array}$ & $\begin{array}{c}\text { Total length } \\
\text { in elevation interval } \\
\text { (km) }\end{array}$ \\
\hline $0-4$ & 2.3 \\
$4-8$ & 3.3 \\
$8-12$ & 12.0 \\
$12-16$ & 3.8 \\
$16-20$ & 6.5 \\
$20-24$ & 3.3 \\
$24-28$ & 3.6 \\
$20-32$ & 4.1 \\
$32-36$ & 10.4 \\
$36-40$ & 3.0 \\
$40-44$ & 2.4 \\
$44-49$ & 2.8 \\
$48-52$ & 1.6 \\
$52-56$ & 0.9 \\
& $65.0 \mathrm{~km}$ \\
\hline
\end{tabular}

The maximum elevation along the PechoraKama Canal alignment is about $56 \mathrm{~m}$ above the projected water level in the Canal (approximately $130 \mathrm{~m}$ above sea level). Reference to Fig. 5 shows that this elevation will require individual yields of $70,90,135$, and $25 \mathrm{C}$ : $i$ to excavate channels having areas of $2000,200,5000$, and $10,000 \mathrm{~m}:$, respectively, assuming no enhancement of crater dimensions as a result of close spacing of the cha:ges. A spacing of $S=1.2 Z$ to $1.3 Z$ is generally believed to lead to row craters having no enhancement of width and depth as compared to single craters produced by the same yield and depth-of-burial. Closer spacing will increase $R_{s}$ and $D_{s}$, thereby decreasing the yields required to excavate the indicated areas.

Application of the curves in Fig. 5 to the topographic data given in Table 2 requires the assumption of a family of yields. Experience has shown that the specific choices of explosive yields are not critical, although larger numbers in the family of explosives generally lead to a somewhat larger total number of explosives. A family of 15 . $30,60,100,150$, and $300 \mathrm{kt}$ explosives was assumed for this calsulation. (See Table 3.) A spacing corresponding to $1.3 \mathrm{Z}$ or $\$ 2 \mathrm{~m} / \mathrm{kt}^{1 / 3.4}$ was assumed. The remainder of Table 3 presents the maximum elevation through which each yicld can excavate a given area, the length of the route with elevations that can be excavated by that explosive, and the total number of explosives required. The larger numbers of explosives for areas of 2000 and $3000 \mathrm{~m}^{2}$ reflect the use of large numbers of small yieids to excavate the lower elevations. When only larger yields are used, as for $A=10,000 \mathrm{~m}^{2}$, the total number of explosives decreases and is comparable with the number cited by Kedrovskiy. Only the $10,000 \mathrm{~m}^{2}$ option, including a safety factir of 2 or 3, requires use of yields in excess of $150 \mathrm{kt}$.

Based on the descriptions of the geologic condition of the Pechora-Kama Canal provided by the Soviets, the cratering properties of the rock in this area appear more favorable than those we assumed for the above example. An alternati'e approach is to assume a crater dimension more representative of saturated, soft rock. For such conditions, the values

TABLE 3. Nuclear design estimates for the Pechora-Kama Canal. These are for dry, hard rock cratering parameters based on U.S. cratering experience. $R_{s}=41 \mathrm{~m} / \mathrm{kt}^{1 / 3.4}, D_{\mathrm{s}}=24 \mathrm{~m} / \mathrm{kt}^{1 / 3.4}$, and $Z_{\mathrm{s}}=40 \mathrm{~m} / \mathrm{kt}^{1 / 3.4}$.

\begin{tabular}{|c|c|c|c|c|c|c|c|c|c|c|c|c|c|}
\hline \multirow{2}{*}{$\underset{(k t)}{W}$} & \multirow{2}{*}{$\begin{array}{l}\text { Spacing } \\
(\mathrm{m})\end{array}$} & \multicolumn{3}{|c|}{$A=2000 \mathrm{~m}^{2}$} & \multicolumn{3}{|c|}{$A=3000 \mathrm{~m}^{2}$} & \multicolumn{3}{|c|}{$A=5000 \mathrm{~m}^{2}$} & \multicolumn{3}{|c|}{$A=10,0 \times 0 \mathrm{~m}^{2}$} \\
\hline & & $\begin{array}{l}E \\
\text { (m) }\end{array}$ & (tm) & $\mathbf{N}$ & $\underset{\text { (m) }}{E}$ & $\underset{(\mathrm{km})}{L}$ & $\mathbf{N}$ & $\underset{(m)}{E}$ & $\underset{(\mathrm{km})}{\mathbf{L}}$ & $\mathbf{N}$ & $\underset{(m)}{E}$ & $\underset{(\mathrm{km})}{\mathbf{L}}$ & $\bar{N}$ \\
\hline 15 & $11 \mathrm{~s}$ & 23 & 35.9 & 312 & 15 & 25.6 & 223 & - & - & - & - & - & - \\
\hline 30 & 141 & 37 & $: 4$ & 138 & 29 & 15.2 & 108 & 16 & 26.4 & 187 & - & - & - \\
\hline 60 & 173 & 53 & 9.0 & 52 & 45 & 19.5 & 113 & $?_{2}$ & 17.5 & 101 & 8 & 10.6 & 61 \\
\hline 100 & 201 & 66 & 0.7 & 3 & 59 & 4.7 & 23 & 46 & 17.2 & 86 & 23 & 24.9 & 124 \\
\hline 150 & 227 & - & - & - & - & - & - & 60 & 3.9 & 17 & 37 & 19.5 & 86 \\
\hline 300 & 278 & - & - & - & - & - & - & - & - & - & 62 & 10.0 & 36 \\
\hline \multicolumn{3}{|c|}{$\begin{array}{l}\text { Total number of } \\
\text { explosives required }\end{array}$} & & 505 & & & 467 & & & 391 & & & 307 \\
\hline
\end{tabular}


from 1004, the Soviet 125-kt nuclear crater, appear to be reasonabie. The values are

$$
\begin{aligned}
& R_{s}=49 \mathrm{~m} / \mathrm{kt}^{1 / 3.4}, \\
& D_{s}=20 \mathrm{~m} / \mathrm{kt}^{1 / 3.4}, \\
& Z_{s}=43 \mathrm{~m} / \mathrm{kt}^{1 / 3.4},
\end{aligned}
$$

and

$$
\mathrm{m}=0.7 \text {. }
$$

These cratering parameters lead to the curves shown in Fig. 7 for elevation, E, as a function of the yield, W. Application of these curves to the profile data in Table 2 leads to the nuclear design estimates given in Table 4. A spacing of 1.32 was also used for inis case. The total number of explo .ves required for this case are somewhat less than the first case (Table 3 ), but still quite comparable. Again, only the $10,000 \mathrm{~m}^{2}$ opsion requires the use of explosives larger than $150 \mathrm{kt}$.

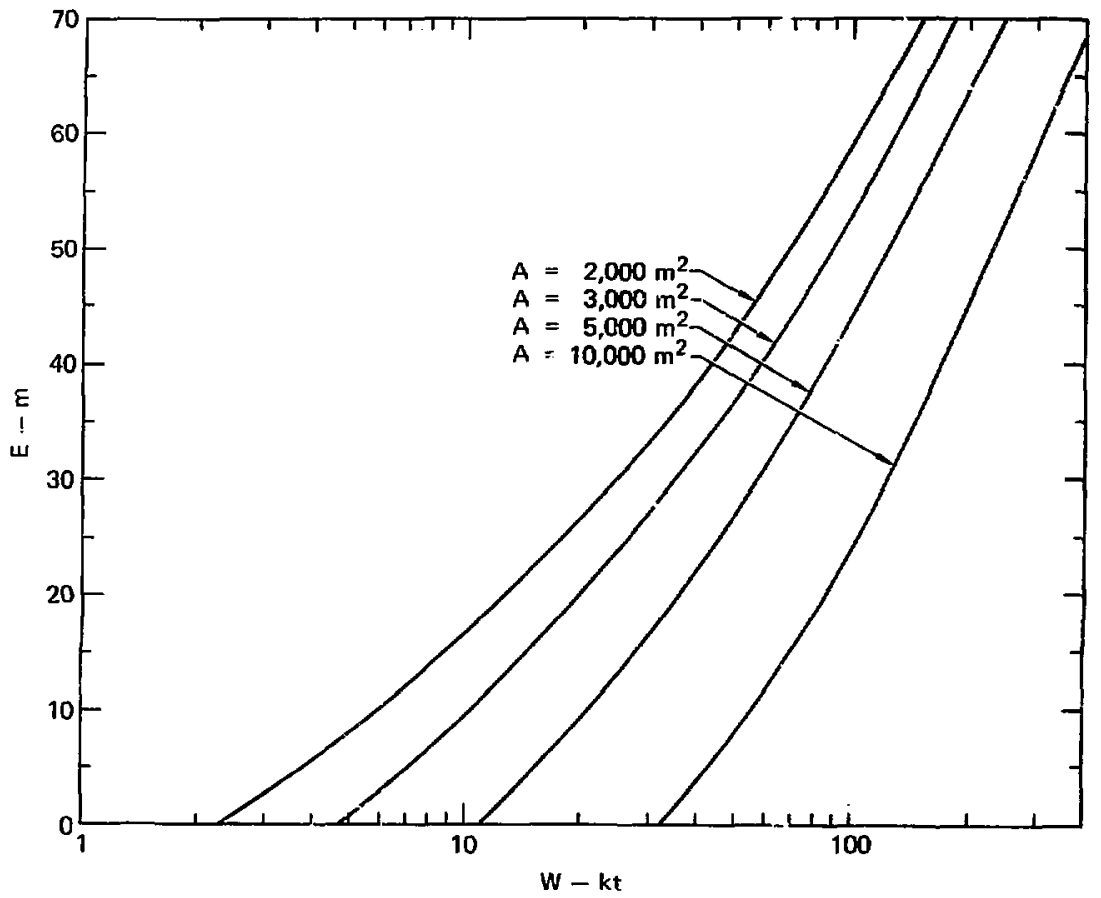

FIG. 7. Water surface elerstion vs yield and cross-sectional area for saturated, soft-rock cratering parameters, 
TABLE 4. Nuclear design estimates for the Pechora-Kama Canal. These are for saturated, soft rock parameters based on U.S. cratering experience. $R_{s}=49 \mathrm{~m} / \mathrm{kt}^{1 / 3.4}, D_{\mathrm{s}}=20 \mathrm{~m} / \mathrm{kt}^{1 / 3.4}$, and $\mathrm{Z}_{\mathrm{s}}=43 \mathrm{~m} / \mathrm{kt}^{1 / 3.4}$.

\begin{tabular}{|c|c|c|c|c|c|c|c|c|c|c|c|c|c|}
\hline \multirow{2}{*}{$\underset{(k t)}{w}$} & \multirow{2}{*}{$\begin{array}{c}\text { Spacing } \\
\text { (m) }\end{array}$} & \multicolumn{3}{|c|}{$\mathrm{A}=2000 \mathrm{~m}^{2}$} & \multicolumn{3}{|c|}{$A=3000 \mathrm{~m}^{2}$} & \multicolumn{3}{|c|}{$A=5000 \mathrm{~m}^{2}$} & \multicolumn{3}{|c|}{$A=10,000 \mathrm{~m}^{2}$} \\
\hline & & $\begin{array}{c}E \\
\text { (m) }\end{array}$ & $\underset{(\mathrm{km})}{\mathrm{L}}$ & $\mathbf{N}$ & $\begin{array}{c}E \\
\text { (m) }\end{array}$ & $\underset{(\mathrm{km})}{\mathbf{L}}$ & $\mathbf{N}$ & $\begin{array}{c}E \\
\text { (m) }\end{array}$ & $\underset{(\mathrm{km})}{\mathrm{L}}$ & $\bar{N}$ & $\begin{array}{c}E \\
(m)\end{array}$ & $\underset{(\mathrm{km})}{\mathrm{L}}$ & $\mathbf{N}$ \\
\hline 15 & 124 & 22 & 34.6 & 279 & 10 & 16.6 & 134 & - & - & $\sim$ & - & - & - \\
\hline 30 & 152 & 33 & 11.9 & 78 & 27 & 22.3 & 147 & 16 & 26.4 & 174 & - & - & - \\
\hline 60 & 186 & 47 & 15.3 & 82 & 41 & 19.0 & 102 & 31 & 16.5 & 89 & 12 & 22.6 & 122 \\
\hline 100 & 216 & 59 & 3.2 & 15 & 52 & 6.2 & 29 & 44 & 16.8 & 78 & 24 & 13.6 & 63 \\
\hline 150 & 244 & - & - & - & 64 & 0.9 & 4 & 56 & 5.3 & 22 & 36 & 18.1 & 74 \\
\hline 300 & 299 & - & - & - & - & - & - & - & - & - & 59 & 10.7 & 36 \\
\hline & $\begin{array}{l}\text { number } \\
\text { losives re }\end{array}$ & & & 454 & & & 416 & & & 363 & & & 295 \\
\hline
\end{tabular}

These cratering parameters are consistent with the Soviet $125-k t$ nuclear crater 1004 .

\section{ESTIMATE BASED ON KEDROVSKIY'S TYPICAL LATERAL CANAL CROSS SECTION}

Using the notation from Fig. 2, we can see that thu Soviets assumed slope failure could occur until the slope reached an angle of $\alpha$ as measured from the horizontal. It was also assumed that the final slope intersects the original crater wall precisely at the original ground surface where the row crater half-width is $R\left(-B_{g} / 2\right.$ in Fig. 2). Thus, the bottom of the triangle representing the useful cross section is at a depth tolow the original ground surface of $R \cdot \tan \alpha$. For a canal passing through terrain having an elevation. $E$, above the desired water surface in the canal, we can see the height of the useful triangular canal cross section (i.e., the depth of the svater) is $H_{x}=R \tan \alpha-E$ and the width of the water bearing section, $B_{x}$, is

$$
B_{x}=\frac{2 H_{x}}{\tan \alpha}
$$

Therefore, the useful aren, $A$, is given by

$$
\mathrm{A}=\frac{\mathrm{B}_{\mathrm{x}} \mathrm{H}_{\mathrm{x}}}{2}=\frac{\mathrm{H}_{\mathrm{x}}^{2}}{\tan \alpha}=\frac{(\mathrm{R} \tan \alpha-\mathrm{E})^{2}}{\tan \alpha} .
$$

Since $R=R_{s} W^{1 / 3.4}$, we can write

$$
W=\frac{1}{R_{s}^{3,4}}\left[\left(\frac{A}{\tan \alpha}\right)^{1 / 2}+\frac{E}{\tan \alpha}\right]^{3.4} .
$$

Thus, the yield, $W$, required to excavate a canal of useful cross section $A$ through an elevation $E$ can be calculated, assuming a value for the scaled crater radius and a firal slope for the sides of the crater, $\alpha$. Figure 8 preselas the variation of elevation, $E$, as a function of yield as given by $\mathrm{Eq}$. (5) for areas of 2000,3000 , and $5000 \mathrm{~m}^{2}$, respectively, and for slope angles with tangents equal to $0.2,0.3$, and 0.4 . These correspond to slope angles of 11,17 , and $22^{\circ}$. Slopes flatter than $20-25^{\circ}$ are not expected in anything but the weakest materials. A value of 49 $\mathrm{m} / \mathrm{kt}^{1 / 3.4}$ fur $R_{\mathrm{s}}$ was used for all calculations.

Using the plots of $E$ vs $W$ from Fig. 8 and the aggregate length intervals from Table 2, we can calculate the explosive requirements to exca vate the Pechora-Kama Canal under this method. Results of these calculations are presented in Tables 5.7 for useful areas of 2000,3000 , and $5000 \mathrm{~m}^{2}$, respectively. A spacing equal to 1.3 times the depth-ofburst of $43 \mathrm{~m} / \mathrm{kt}^{1 / 3.4}$ was used for all these calculations.

The results range quite widely, depending on the assumption for input numbers. The use of $\mathrm{m}=$ 0.4 , a reasonable (or even conservative) value for 

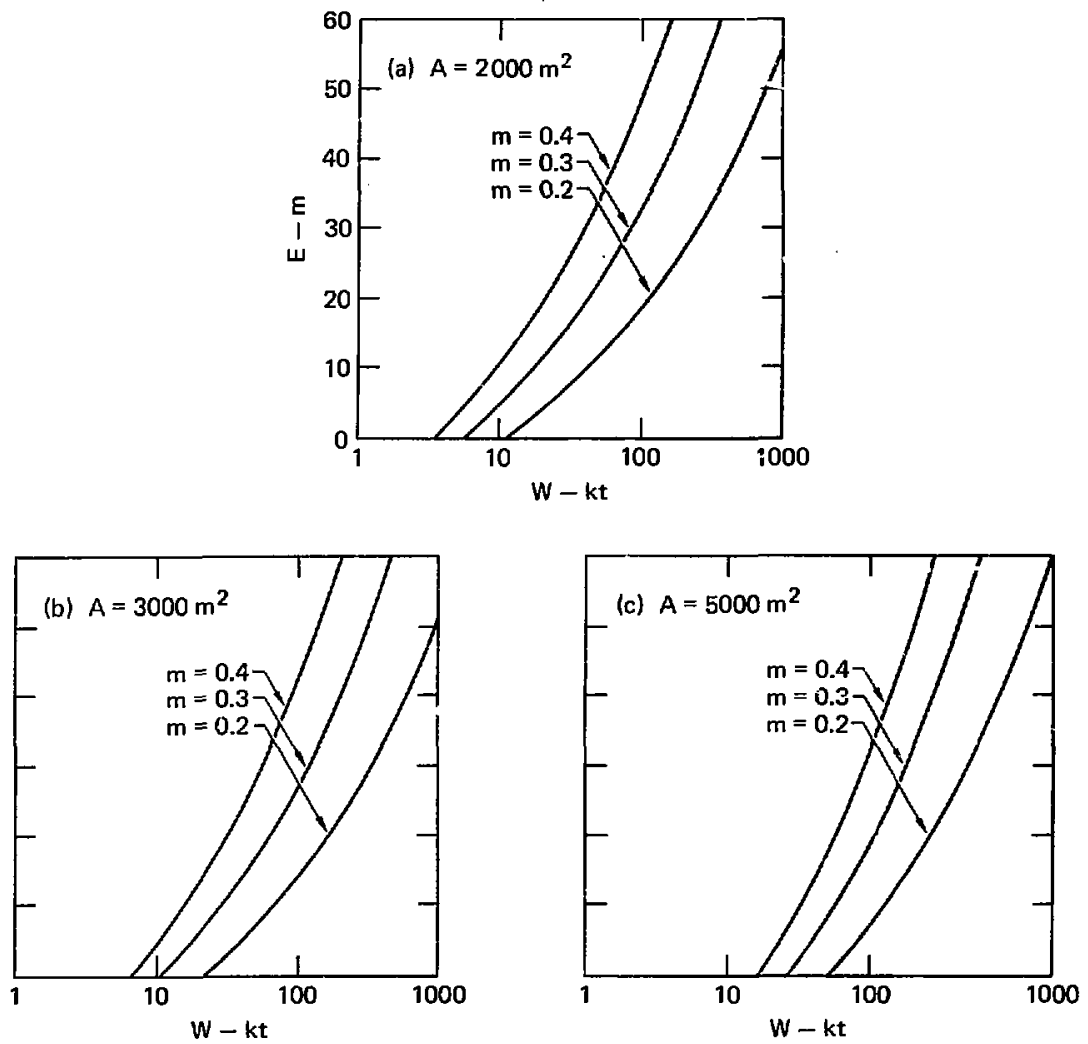

FIG. 8. Water surface elevation vs yield and slope angle a for cross-sectional areas of (a) $2000 \mathrm{~m}^{2}$, (b) $3000 \mathrm{~m}^{2}$, and $(\mathrm{c}) 5000 \mathrm{~m}^{2}$.

most of the types of materials indicated in Fig. I and one which corre.ponds to the slope used in Fig. 2, gives results that are quite comparable with the yalues quoted by Kedrovskiy for the $5000 \mathrm{~m}^{2}$ canal (i.e., 28.7 vs $36 \mathrm{Mt}$ and 325 vs 250 explosive). Further, the results indicate that yields above $150 \mathrm{kt}$ are only required for the 3000 and $5000 \mathrm{~m}^{2}$ options, not for the $2600 \mathrm{~m}^{2}$ one. However, the results from this method are very sensitive to the choice of final slope angle and any angle flatter than $30^{\circ}$ will require an explosive larger than $150 \mathrm{kt}$ for all current cross section options. 
TABlE 5. Nuclear design estimates for the PechoraKama Canal. The estimates are based on Kerirovskiy's lateral canal cross section with final slopes of $m=0.4$ and 0.2 , and $R_{s}=49 \mathrm{~m} / \mathrm{kt}^{1 / 3.4}$.

\begin{tabular}{|c|c|c|c|c|c|c|c|}
\hline \multicolumn{8}{|c|}{$A=2000 \mathrm{~m}^{2}$} \\
\hline \multirow{2}{*}{$\underset{(k t)}{w}$} & \multirow{2}{*}{$\begin{array}{l}\text { Spacing } \\
\text { (m) }\end{array}$} & \multicolumn{3}{|c|}{$\mathrm{m}=0.4$} & \multicolumn{3}{|c|}{$\mathrm{m}=0.2$} \\
\hline & & $\begin{array}{c}\mathbf{E} \\
\text { (ID) }\end{array}$ & $\begin{array}{c}L \\
(\mathrm{~km})\end{array}$ & $\mathbf{N}$ & $\begin{array}{c}\mathbf{E} \\
\text { (m) }\end{array}$ & $\begin{array}{c}\mathrm{L} \\
(\mathrm{km})\end{array}$ & $\overline{\mathbf{N}}$ \\
\hline 15 & 124 & 16 & 26.4 & 213 & 2 & 1.2 & 10 \\
\hline 30 & 152 & 26 & 11.5 & 76 & 6 & 5.3 & 35 \\
\hline 60 & 186 & 38 & 17.9 & 96 & 13 & 17.1 & 92 \\
\hline 100 & 216 & 48 & 6.7 & 31 & 18 & 6.0 & 28 \\
\hline 150 & 244 & 58 & 2.5 & 10 & 23 & 6.3 & 26 \\
\hline 300 & 299 & - & - & - & 33 & 10.6 & 35 \\
\hline 600 & 366 & - & - & - & 45 & 13.9 & 38 \\
\hline \multirow[t]{2}{*}{1000} & 426 & - & - & - & 55 & 4.6 & 11 \\
\hline & & & & 426 & & & 275 \\
\hline \multicolumn{3}{|c|}{ Total yield (Mt) } & & 15.8 & & & 56.6 \\
\hline
\end{tabular}

TABLE 6. Nuclear design estimates for the PechoraKama Canal. The estimates are based on Kedrovskiy's lateral canal cross section with final siopes of $m=0.4$ and 0.2 , and $R_{8}=49 \mathrm{~m} / \mathrm{kt}^{1 / 3.4}$

\begin{tabular}{|c|c|c|c|c|c|c|c|}
\hline \multicolumn{8}{|c|}{$A=3000 \mathrm{~m}^{2}$} \\
\hline \multirow{2}{*}{$\underset{(x i)}{W}$} & \multirow{2}{*}{$\begin{array}{l}\text { Spacing } \\
\text { (m) }\end{array}$} & \multicolumn{3}{|c|}{$m=0.4$} & \multicolumn{3}{|c|}{$\mathrm{m}=0.2$} \\
\hline & & $\begin{array}{c}E \\
\text { (m) }\end{array}$ & $\begin{array}{c}L \\
(\mathrm{~km})\end{array}$ & $\mathbf{N}$ & $\begin{array}{c}E \\
(m)\end{array}$ & $\begin{array}{c}\mathbf{L} \\
(\mathrm{km})\end{array}$ & $\mathbf{N}$ \\
\hline 15 & 124 & 10 & 16.6 & 134 & - & - & - \\
\hline 30 & 152 & 19 & 14.6 & 96 & 2 & 1.2 & 8 \\
\hline 60 & 186 & 31 & 11.6 & 62 & 8 & 9.4 & 51 \\
\hline 100 & 216 & 42 & 15.7 & 73 & 13 & 129 & 50 \\
\hline 150 & 244 & 51 & 5.2 & 21 & 18 & 6.1 & 25 \\
\hline 300 & 299 & 70 & 1.3 & 4 & 28 & 10.2 & 34 \\
\hline 600 & 366 & - & - & - & 40 & 17.5 & 48 \\
\hline 1000 & 426 & - & - & - & 50 & 6.0 & 14 \\
\hline \multirow[t]{2}{*}{1500} & 480 & - & - & $=$ & 60 & 1.7 & 4 \\
\hline & & & & 390 & & & 244 \\
\hline & $I$ yield $(\mathrm{Mt}$ & & & 20.3 & & & 72.0 \\
\hline
\end{tabular}

TABLE 7. Nuclear design estimates for the PechoraKama Canal. The estimates are based on Kedrovskiy's lateral canal cross section with final slopes of $m=0.4$ and 0.2 , and $R_{s}=49 \mathrm{~m} / \mathrm{kt}^{1 / 3.4}$.

\begin{tabular}{|c|c|c|c|c|c|c|c|}
\hline \multicolumn{8}{|c|}{$A=5000 \mathrm{~m}^{2}$} \\
\hline \multirow{2}{*}{$\begin{array}{r}W \\
(\mathbf{k t})\end{array}$} & \multirow{2}{*}{$\begin{array}{l}\text { Spacing } \\
\text { (m) }\end{array}$} & \multicolumn{3}{|c|}{$\mathbf{m}=\mathbf{0 . 4}$} & \multicolumn{3}{|c|}{$\mathrm{m}=0.2$} \\
\hline & & $\begin{array}{c}E \\
\text { (iin) }\end{array}$ & $\begin{array}{c}L \\
(\mathbf{k m})\end{array}$ & $\mathbf{N}$ & $\begin{array}{c}E \\
\text { (m) }\end{array}$ & $\begin{array}{c}\mathrm{L} \\
\text { (km) }\end{array}$ & $\mathbf{N}$ \\
\hline 30 & 152 & 8 & 10.6 & 70 & - & - & - \\
\hline 60 & 186 & 21 & 23.1 & 124 & I & 0.6 & 3 \\
\hline 100 & 216 & 31 & 9.1 & 42 & 6 & 5.9 & 27 \\
\hline 150 & 244 & 47 & 19.0 & 78 & 14 & 18.0 & 74 \\
\hline 300 & 299 & 60 & 3.2 & 11 & 21 & 9.2 & 31 \\
\hline 600 & 366 & - & - & - & 32 & 10.2 & 28 \\
\hline 1000 & $4: 6$ & - & - & - & 43 & 15.2 & 36 \\
\hline 1590 & 480 & - & - & - & 52 & S.0 & 10 \\
\hline 2000 & 522 & - & - & - & 60 & 0.9 & 2 \\
\hline & & & & 325 & & ’ & 211 \\
\hline & 1 yield 0 & & & 28.7 & & & 95.1 \\
\hline
\end{tabular}




\section{CONCLUSIONS}

Estimates of the ri!clear explosive requirements for the Pechora-Kama Canal, based on the crude profile and geologic section provided by the Soviets, indicate that the nuclear canal can be constructed to meet all identiffed criteria entirely with nuclear explosives with yields less than or equal to $150 \mathrm{kt}$. The total numbers of explosives estimated in this report are, in general, larger than those provided in 1970-71 by Kedrovskiy. This larger number indicates that either 1) a ruch larger canal was contemplated, 2) a very large safety factor was included to provide for scalloping or slumping, or 3) the use of explosives larger than the minimum required for the given elevation and cross section were planned. The last course of action appears the most probable since it is both the minimum cost and minimum radioactivity release design.

\section{REFERENCES}

1. M. D. Nordyke, "A Review of Soviet Data on the Peaceful Uses of Nuclear Explosions," Annals of Nuclear Energy' 2, 657-673 (1975).

2. O. L. Kedrovskiy, "The Application of Cratering Explosions in Industry and Construction," in Proc. of the Peaceful Nuclear Explosives Panel I, 1970 (IAEA, Vienna, Austria, 1970), paper IAEA-PL-388/2I, 377.404 .

3. O. L. Kedrov skiy and I. D. Morokhov, Soviet State Comm. for Atomic Energy, U.S.S.R., to G. Werth, Lawrence Livermore Laboratory, Livermore, Calif., private communication (1970).

4. V. V. Kireev, O. L. Kedrovskiy, Y. A. Valentinov, K. V. Myasnikov, G. A. Nikiforov, L. B. Prozorov, and V. K. Potapov, "Multiple Nuclear Explosions for Excavations in Alluvial Rocks," in Proc, of a Technical Comm.-Peaceful Nuclear Explosives IV, 1975 (IAEA, Vienna, Austria, 1975), paper TC-14/14, 399-417.

5. I. P. Pasechnik and K. V. Myasnikov, Institute of Earth Physics, U.S.S.R., private communication (1977).

6. B. C. Hughes, Nuclear Construction Engineering Technology. U.S. Army Engineers Nuclear Cratering Group, Livermore, Calif., NCG Technology Report No. 2 (1968). 